\title{
A population-based propensity-matched study of regional dissections in patients with metastatic osteosarcoma
}

\author{
Wenjuan Wang ${ }^{1 \dagger}$, Hongzhi Ding ${ }^{1 \dagger}$, Zhenyu Sun ${ }^{1 \dagger}$, Chen $\mathrm{Jin}^{2}$, Yanhui Zhu ${ }^{2^{*}}$ and Xiang Wang ${ }^{2^{*}}$ (D)
}

\begin{abstract}
Background: The survival rates of patients with metastatic osteosarcoma are poor, and the prognosis is closely related to the choice of treatment, especially surgery. This study aimed to evaluate the survival outcomes of patients with metastatic osteosarcoma undergoing regional dissections.

Methods: We collected data on patients with metastatic osteosarcoma between 2004 and 2014 from the Surveillance, Epidemiology, and End Results (SEER) database. Kaplan-Meier curves were used to compare overall survival (OS) and cancer-specific survival (CSS), while univariate and multivariate Cox regression analyses were used to evaluate outcomes. Propensity score matching (PSM) was used to minimize the effects of confounding factors.

Results: The SEER database had records of 2768 patients diagnosed with osteosarcoma, of whom 398 were included in our study. Of the included patients, 116 (29.15\%) underwent regional dissections, while 282 (70.85\%) underwent non-regional dissections. The univariate and multivariate Cox regression analyses, prior to PSM, showed that OS (hazard ratio (HR): 0.34, 95\% confidence interval (Cl): 0.26-0.44, $\mathrm{P}<0.001$ and HR: $0.47,95 \%$ Cl: 0.35-0.64, $\mathrm{P}<$ 0.001, respectively) and CSS (HR: 0.33, 95\% Cl: $0.25-0.43, \mathrm{P}<0.001$ and HR: $0.46,95 \% \mathrm{Cl}: 0.34-0.63, \mathrm{P}<0.001$, respectively) were better in patients who underwent regional dissections than those who underwent non-regional dissections. Compared with non-regional dissections, regional dissections, which included both primary tumour resection (PTR) and primary tumour and metastatic site resection (PTMR), were associated with better OS $(\mathrm{P}<0.001)$ and CSS $(P<0.001)$. However, the survival outcomes following PTR and PTMR showed no significant difference. After PSM, patients in the regional dissection group still had a higher OS $(P<0.001)$ and CSS $(P<0.001)$ than those in the non-regional dissection group.
\end{abstract}

Conclusions: Compared with non-regional dissection, regional dissection resulted in better survival in patients with metastatic osteosarcoma.

Keywords: metastatic osteosarcoma, regional dissection, primary tumours, SEER, overall survival, cancer-specific survival

\section{Introduction}

Osteosarcoma is the most common primary malignant bone tumour in children and adolescents [1]. It is characterized by rapid progression, early pulmonary metastasis, poor prognosis and recurrence [2-4]. While the 5-year survival rate of patients with osteosarcoma is approximately

\footnotetext{
* Correspondence: zhuyanhui1981@yeah.net; wx20022005@outlook.com †Wenjuan Wang, Hongzhi Ding and Zhenyu Sun contributed equally to this work.

${ }^{2}$ Department of Orthopaedic Surgery, Shanghai Ninth People's Hospital, Shanghai Jiao Tong University School of Medicine, Shanghai, China Full list of author information is available at the end of the article
}

$65 \%$, that of patients with metastatic osteosarcoma is only $25 \%$ [5]. The poor prognosis in patients with metastatic osteosarcoma highlights the need for a more effective therapy to treat both primary and metastatic tumours and to improve the patients' quality of life and survival rates. Though advanced chemotherapy has the potential to increase the overall survival (OS), it is, however, not as effective by itself in the absence of surgical resection [6].

While the survival factors associated with metastatic osteosarcoma are complex and controversial, surgical resection is widely accepted as a beneficial treatment 
method. Some retrospective studies have reported the benefits of primary tumour resection (PTR) and primary tumour and metastatic site resection (PTMR) [7-9]. In general, surgical resection, combined with chemotherapy, has been shown to result in better prognosis [10, 11]. However, whether surgery is beneficial for stage IV osteosarcoma patients with extensive metastases remains unclear. There have been studies that have favoured non-resection therapies, such as chemotherapy or radiotherapy, for patients with multiple unresectable metastases $[2,12]$. Surgical resection is not always feasible due to challenges such as large tumours, various sites of origin, poor physical condition, and various complications after resection. In particular, when the expected survival time is less than three months after surgery, surgical resection is not an optimal alternative. The choice of surgical resection in patients with metastatic osteosarcoma has, therefore, not been widely reported.

Despite these controversies, we used the available data on patients with metastatic osteosarcoma in the United States from the Surveillance, Epidemiology, and End Results (SEER) database, to evaluate the OS and cancerspecific survival (CSS) and to determine if regional dissections are beneficial for these patients. We believe that our findings would help with the selection of the right surgical treatment and thereby improve the prognosis for metastatic osteosarcoma.

\section{Methods}

\section{Data source}

The SEER database supported by the National Cancer Institute includes data on patients with metastatic osteosarcoma such as the patient demographics, treatments, and survival times. For our analysis, we collected data from 18 population-based cancer registries of the SEER database (1973-2014 dataset), accounting for 30\% of the US population.

\section{Inclusion and exclusion criteria}

The patients included in the study (1) had osteosarcoma, which was the only cancer that was included, (2) were diagnosed from 2004 to 2014, (3) had a survival time of $>3$ months, (4) were eligible for a specific treatment of primary tumours, and (5) had other synchronous cancers along with osteosarcoma. Patients not diagnosed with stage IV osteosarcoma were excluded from the study.

\section{Institutional Review Board approval}

Data used in this study were obtained from the SEER database. The private SEER ID (13130-Nov 2017) was used to support our analysis. All procedures performed in studies involving human participants were in accordance with the ethical standards of the Institutional and/ or National Research Committee and with the 1964
Helsinki declaration and its later amendments or comparable ethical standards.

\section{Propensity score matching}

We used propensity score matching (PSM) to avoid the use of unbalanced basic patient variables and thereby avert a selection bias. First, a logistic regression model was set up, and regional dissection was regarded as the dependent variable. Table 1 summarizes the baseline characteristics of the included patients. Next, patients who underwent regional dissections were matched with those who had not undergone regional dissections based on the calculated scores with a greedy algorithm of the nearest matched neighbour at a fixed ratio of 1:1. After matching, we checked if these covariates were balanced on the basis of absolute values. An absolute value $<0.1$ was indicative of a good balance between the two groups.

\section{Statistical analyses}

In our analysis, OS and CSS were regarded as the standard results. The Kaplan-Meier plot was used to estimate and plot the survival curves. The curves of the regional dissection and non-regional dissection groups were compared using the log-rank test. Variables with $\mathrm{P}$ values $<0.05$ in the univariate analysis were subsequently used in the multivariate analysis. A Cox proportional hazards model was established before matching. The outcomes were presented as 95\% confidence intervals (CIs) and hazard ratios (HRs). All analyses were two-sided and were performed using the SPSS software (version 23.0; IBM, NY), and P < 0.05 was considered statistically significant.

\section{Results}

\section{Patient characteristics}

The SEER database had records of 2,768 patients with osteosarcomas between 2004 and 2014. On the basis of the inclusion and exclusion criteria, 398 out of these 2,768 patients were included in our analysis. The process of patient selection is shown in Fig. 1. The baseline characteristics of the 398 patients included in the study are shown in Table 1 . Approximately $59.80 \%$ of the patients were men, and $77.14 \%$ of them belonged to the white race. In total, 116 patients underwent regional dissections, and 282 underwent non-regional dissections. Furthermore, approximately $93.47 \%$ and $16.08 \%$ of the patients underwent chemotherapy and radiation, respectively.

\section{Survival analyses before population matching}

The OS in patients who underwent different treatments (non-regional dissection vs regional dissection) was analysed using the Kaplan-Meier method (Fig. 2a). The curves showed that prior to PSM, the OS was better in the regional dissection group than in the non-regional dissection group $(\mathrm{P}<0.001)$ (Fig. 2). Patients who 
Table 1 Characteristics of patients with metastatic osteosarcoma included in this study

\begin{tabular}{|c|c|c|c|}
\hline \multirow[t]{2}{*}{ Characteristics } & Total & Regional dissection & Non-regional dissection \\
\hline & $\begin{array}{l}398 \\
(100 \%)\end{array}$ & $\begin{array}{l}116 \\
(29.15 \%)\end{array}$ & $\begin{array}{l}282 \\
(70.85 \%)\end{array}$ \\
\hline \multicolumn{4}{|l|}{ Sex } \\
\hline Female & $160(40.20 \%)$ & $51(43.97 \%)$ & 109 (38.65\%) \\
\hline Male & $238(59.80 \%)$ & $65(56.03 \%)$ & $173(61.35 \%)$ \\
\hline \multicolumn{4}{|l|}{ Race } \\
\hline White & 307 (77.14\%) & $94(81.03 \%)$ & $213(75.53 \%)$ \\
\hline Black & $59(14.82 \%)$ & $12(10.34 \%)$ & $47(16.67 \%)$ \\
\hline Other race & 32 (8.04\%) & $10(8.62 \%)$ & $22(7.80 \%)$ \\
\hline \multicolumn{4}{|l|}{ Age } \\
\hline$<18$ & $221(55.53 \%)$ & $38(32.76 \%)$ & $183(64.89 \%)$ \\
\hline $18-65$ & 147 (36.93\%) & $62(53.45 \%)$ & 85 (30.14\%) \\
\hline$>=65$ & $30(7.54 \%)$ & $16(13.79 \%)$ & $14(4.96 \%)$ \\
\hline \multicolumn{4}{|l|}{ Grade } \\
\hline Well/moderate & $11(2.76 \%)$ & $5(4.31 \%)$ & $6(2.13 \%)$ \\
\hline Poorly/undifferentiated & $290(72.86 \%)$ & $76(65.52 \%)$ & $214(75.89 \%)$ \\
\hline Unknown & $97(24.37 \%)$ & $35(30.17 \%)$ & $62(21.99 \%)$ \\
\hline \multicolumn{4}{|l|}{ T Stage } \\
\hline $\mathrm{T} 1$ & $67(16.83 \%)$ & $21(18.10 \%)$ & $46(16.31 \%)$ \\
\hline $\mathrm{T} 2$ & $220(55.28 \%)$ & $44(37.93 \%)$ & $176(62.41 \%)$ \\
\hline T3 & $26(6.53 \%)$ & $9(7.76 \%)$ & $17(6.03 \%)$ \\
\hline Tx & $85(21.36 \%)$ & $42(36.21 \%)$ & $43(15.25 \%)$ \\
\hline \multicolumn{4}{|l|}{ Chemotherapy } \\
\hline No/unknown & $26(6.53 \%)$ & $12(10.34 \%)$ & $14(4.96 \%)$ \\
\hline Yes & 372 (93.47\%) & $104(89.66 \%)$ & 268 (95.04\%) \\
\hline \multicolumn{4}{|l|}{ Radiation } \\
\hline No/unknown & 334 (83.92\%) & 79 (68.10\%) & 255 (90.43\%) \\
\hline Yes & $64(16.08 \%)$ & 37 (31.90\%) & 27 (9.57\%) \\
\hline \multicolumn{4}{|l|}{ Location } \\
\hline Extremity & 326 (81.91\%) & $71(61.21 \%)$ & 255 (90.43\%) \\
\hline Other & 72 (18.09\%) & 45 (38.79\%) & 27 (9.57\%) \\
\hline
\end{tabular}

underwent regional dissection were also found to have a better CSS than those who did not $(\mathrm{P}<0.001)$ (Fig. 2b).

The reliability of the survival results was verified by univariate analysis. We found that patients in the regional dissection group had better OS (HR: 0.34, 95\% CI: 0.26-0.44, $\mathrm{P}<0.001$ ) and CSS (HR: 0.33, 95\% CI: 0.25$0.43, \mathrm{P}<0.001)$ those in the non-regional dissection group (Table 2). In addition, radiation and location factors were found to influence the OS and CSS (Table 2). Interestingly, the multivariate Cox regression analysis revealed that patients who underwent lymph node dissections had a higher OS (HR: 0.47, 95\% CI: 0.35-0.64, P $<0.001$ ) and CSS (HR: 0.46, 95\% CI: 0.34-0.63, P < 0.001) (Table 3). Based on the $\mathrm{P}$ values, age at diagnosis was found to be a potential risk factor for the development of primary metastatic osteosarcoma (Table 3).

To identify the specific therapies that effectively improved survival rates, we divided the regional dissection group into two subgroups: PTR and PTMR. As shown in Fig. 3, both the subgroups had better survival (OS or CSS) than the non-regional dissection group $(\mathrm{P}<0.001)$. However, no significant difference was observed in the survival outcomes between the PTR and PTMR subgroups.

\section{Survival analyses after population matching}

Several confounding factors were eliminated by PSM. The results of the test for standardised bias across 


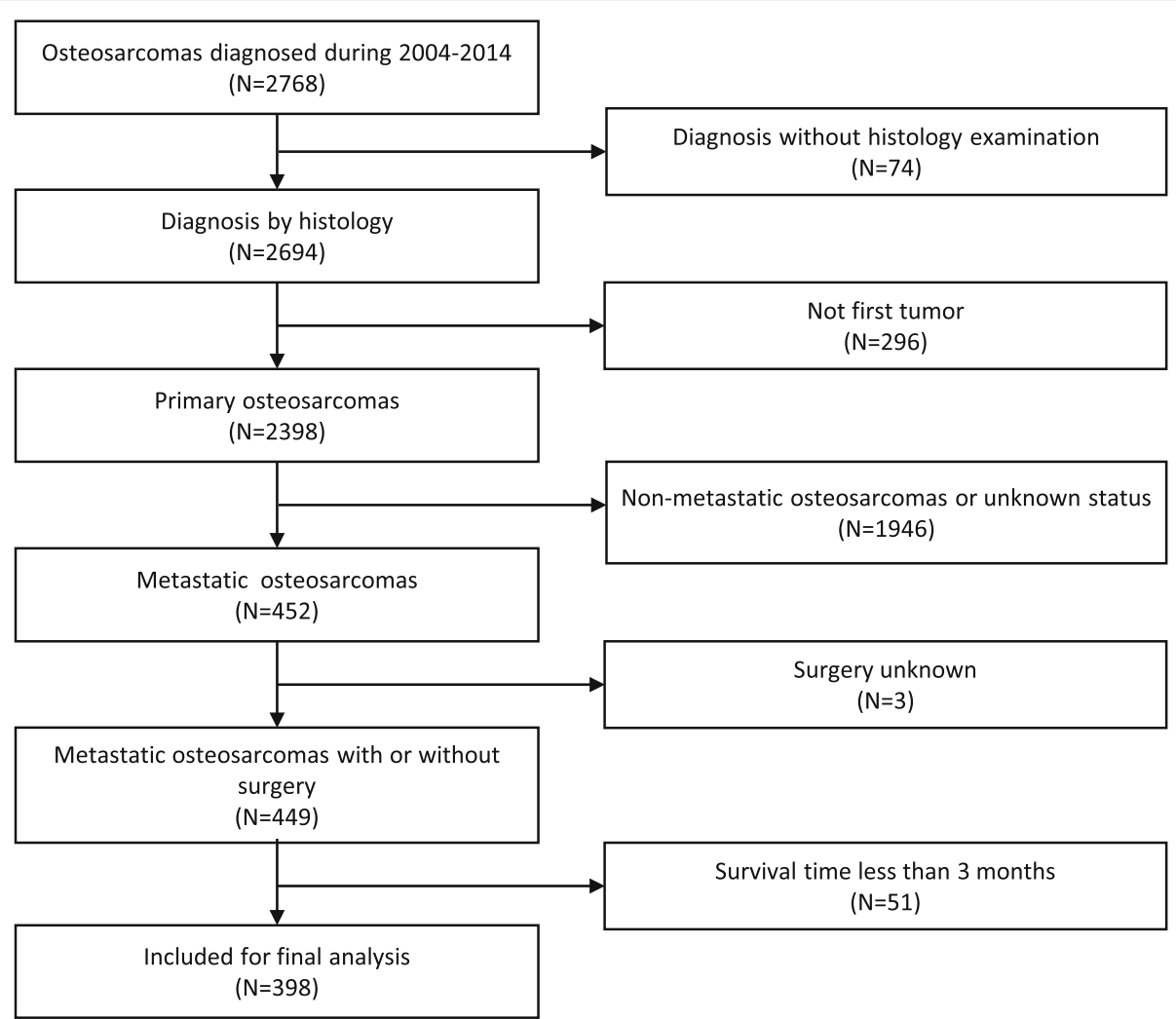

Fig. 1 Flow chart showing the patient selection process

covariates before and after PSM at a 1:1 fixed ratio showed that candidate covariates were well matched (Fig. 4). The Kaplan-Meier curves for OS and CSS showed that patients who underwent regional dissections had better OS and CSS than those who did not undergo regional dissections (Fig. 5).

\section{Discussion}

Our results showed that regional dissection played an essential role in improving the prognosis in patients with metastatic osteosarcoma. Moreover, patients who underwent PTR or PTMR had higher survival rates than those who did not undergo regional resection.

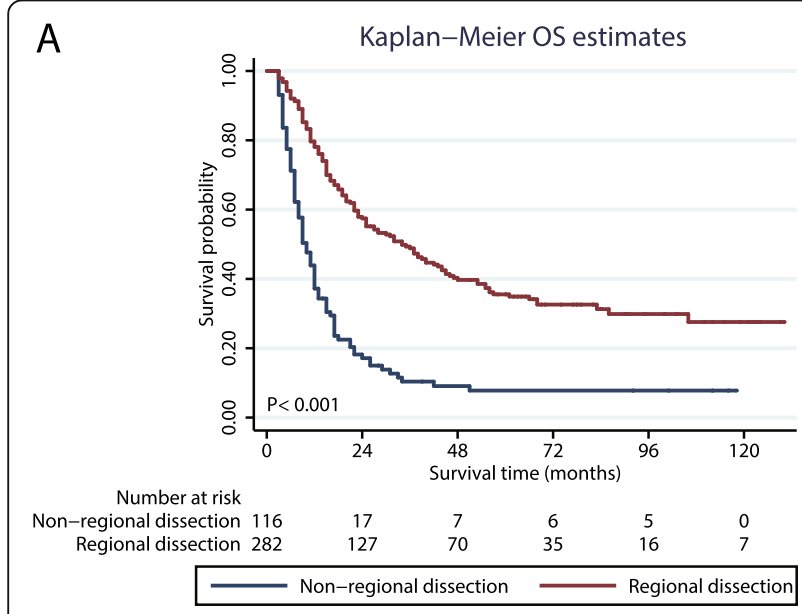

B

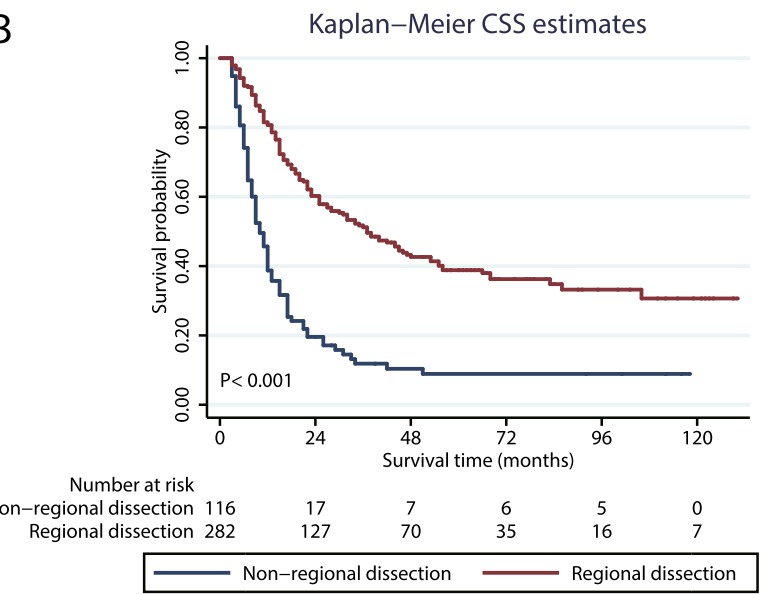

Fig. 2 Kaplan-Meier survival analysis. Shown are curves comparing the (a) OS and (b) CSS in metastatic osteosarcoma patients who underwent regional dissection and those who did not undergo regional dissection. OS: overall survival; CSS: cause-specific survival 
Table 2 Univariate Cox regression analysis for evaluating the influence of Regional dissection on survival of patients with primary metastatic osteosarcoma in SEER database

\begin{tabular}{|c|c|c|c|c|}
\hline \multirow[t]{2}{*}{ Characteristics } & \multicolumn{2}{|l|}{ OS } & \multicolumn{2}{|l|}{ CSS } \\
\hline & $\mathrm{HR}(95 \% \mathrm{Cl})$ & $P$ & $\mathrm{HR}(95 \% \mathrm{Cl})$ & $P$ \\
\hline \multicolumn{5}{|l|}{ Treatment } \\
\hline Non-regional dissection & Reference & & Reference & \\
\hline Regional dissection & $0.34(0.26-0.44)$ & $<0.001$ & $0.33(0.25-0.43)$ & $<0.001$ \\
\hline \multicolumn{5}{|l|}{ Sex } \\
\hline Female & Reference & & Reference & \\
\hline Male & $1.00(0.78-1.29)$ & 0.980 & $1.03(0.79-1.33)$ & 0.851 \\
\hline \multicolumn{5}{|l|}{ Race } \\
\hline White & Reference & & Reference & \\
\hline Black & $0.77(0.53-1.12)$ & 0.170 & $0.72(0.48-1.08)$ & 0.114 \\
\hline Other race & $1.29(0.82-2.02)$ & 0.268 & $1.39(0.89-2.18)$ & 0.152 \\
\hline \multicolumn{5}{|l|}{ Age } \\
\hline$<18$ & Reference & & Reference & \\
\hline $18-65$ & $2.16(1.66-2.80)$ & $<0.001$ & $2.14(1.63-2.81)$ & $<0.001$ \\
\hline$>=65$ & $4.11(2.65-6.38)$ & $<0.001$ & $4.48(2.88-6.98)$ & $<0.001$ \\
\hline \multicolumn{5}{|l|}{ Grade } \\
\hline Well/moderate & Reference & & Reference & \\
\hline Poorly/undifferentiated & $0.53(0.28-1.00)$ & 0.049 & $0.48(0.25-0.91)$ & 0.024 \\
\hline Unknown & $0.65(0.34-1.27)$ & 0.212 & $0.61(0.31-1.19)$ & 0.148 \\
\hline \multicolumn{5}{|l|}{ T Stage } \\
\hline $\mathrm{T} 1$ & Reference & & Reference & \\
\hline $\mathrm{T} 2$ & $0.97(0.68-1.39)$ & 0.884 & $0.97(0.67-1.39)$ & 0.855 \\
\hline T3 & $1.48(0.84-2.59)$ & 0.171 & $1.56(0.88-2.75)$ & 0.121 \\
\hline Tx & $1.26(0.84-1.88)$ & 0.269 & $1.13(0.74-1.72)$ & 0.584 \\
\hline \multicolumn{5}{|l|}{ Chemotherapy } \\
\hline No/unknown & Reference & & Reference & \\
\hline Yes & $0.53(0.34-0.83)$ & 0.005 & $0.49(0.31-0.76)$ & 0.001 \\
\hline \multicolumn{5}{|l|}{ Radiation } \\
\hline No/unknown & Reference & & Reference & \\
\hline Yes & $2.20(1.62-2.99)$ & $<0.001$ & $2.20(1.60-3.03)$ & $<0.001$ \\
\hline \multicolumn{5}{|l|}{ Location } \\
\hline Extremity & Reference & & Reference & \\
\hline Other & $2.53(1.89-3.41)$ & $<0.001$ & $2.50(1.84-3.41)$ & $<0.001$ \\
\hline
\end{tabular}

To the best of our knowledge, this is the first study to report an association between regional dissections at the primary site and better survival in patients with metastatic osteosarcoma based on data from the SEER database. While some previous studies have evaluated the available treatments for metastatic osteosarcoma [6, 13$15]$, they are considered to be outdated and inadequate, given the development of various new diagnostic and surgical technologies. Hence, updating this data is important to make it relevant. Our analysis was based on data from 2004 to 2014 and used novel methods, such as PSM to reduce the effects of confounding factors.

Our finding that regional dissection of metastatic osteosarcoma can improve the OS in patients is consistent with previous findings [6]. Kempf-Bielack et al. [16] reported improvements in patient survival following surgical treatments. Patients who did not receive any surgical interventions were at a higher risk of mortality than those who underwent complete surgical dissection of all the detected tumours [17]. Although the relationship between surgical dissection 
Table 3 Multivariate Cox regression analysis for evaluating the influence of Regional dissection on survival of patients with primary metastatic osteosarcoma in SEER database

\begin{tabular}{|c|c|c|c|c|}
\hline \multirow[t]{2}{*}{ Characteristics } & \multicolumn{2}{|l|}{ OS } & \multicolumn{2}{|l|}{ CSS } \\
\hline & $\mathrm{HR}(95 \% \mathrm{Cl})$ & $P$ & HR $(95 \% \mathrm{Cl})$ & $P$ \\
\hline \multicolumn{5}{|l|}{ Treatment } \\
\hline Non-regional dissection & Reference & & Reference & \\
\hline Regional dissection & $0.47(0.35-0.64)$ & $<0.001$ & $0.46(0.34-0.63)$ & $<0.001$ \\
\hline \multicolumn{5}{|l|}{ Age } \\
\hline$<18$ & Reference & & Reference & \\
\hline $18-65$ & $1.79(1.36-2.36)$ & $<0.001$ & $1.77(1.32-2.36)$ & $<0.001$ \\
\hline$>=65$ & $2.39(1.40-4.06)$ & 0.001 & $2.54(1.48-4.36)$ & 0.001 \\
\hline \multicolumn{5}{|l|}{ Grade } \\
\hline Well/moderate & Reference & & Reference & \\
\hline Poorly/undifferentiated & $0.86(0.44-1.65)$ & 0.644 & $0.80(0.41-1.54)$ & 0.496 \\
\hline Unknown & $0.80(0.41-1.59)$ & 0.531 & $0.76(0.38-1.50)$ & 0.423 \\
\hline \multicolumn{5}{|l|}{ Chemotherapy } \\
\hline No/unknown & Reference & & Reference & \\
\hline Yes & $0.98(0.57-1.67)$ & 0.939 & $0.93(0.54-1.59)$ & 0.779 \\
\hline \multicolumn{5}{|l|}{ Radiation } \\
\hline No/unknown & Reference & & Reference & \\
\hline Yes & $1.25(0.88-1.78)$ & 0.210 & $1.22(0.85-1.76)$ & 0.285 \\
\hline \multicolumn{5}{|l|}{ Location } \\
\hline Extremity & Reference & & Reference & \\
\hline Other & $1.28(0.90-1.83)$ & 0.166 & $1.24(0.86-1.79)$ & 0.253 \\
\hline
\end{tabular}

Abbreviation: SEER=Surveillance, Epidemiology and End Results; OS=Overall survival; CSS=Cause-specific survival

and better survival remained unclear, the phenomenon was supported by some theories. The Halsted theory revealed that tumours spread in an orderly pattern and extended in an adjacent fashion from the primary tumour through the lymphatics to the lymph nodes and then to distant sites [18]. In contrast, other studies have suggested that the growth and metastasis of primary tumours may be complicated and multidirectional $[19,20]$. Kim et al. showed that
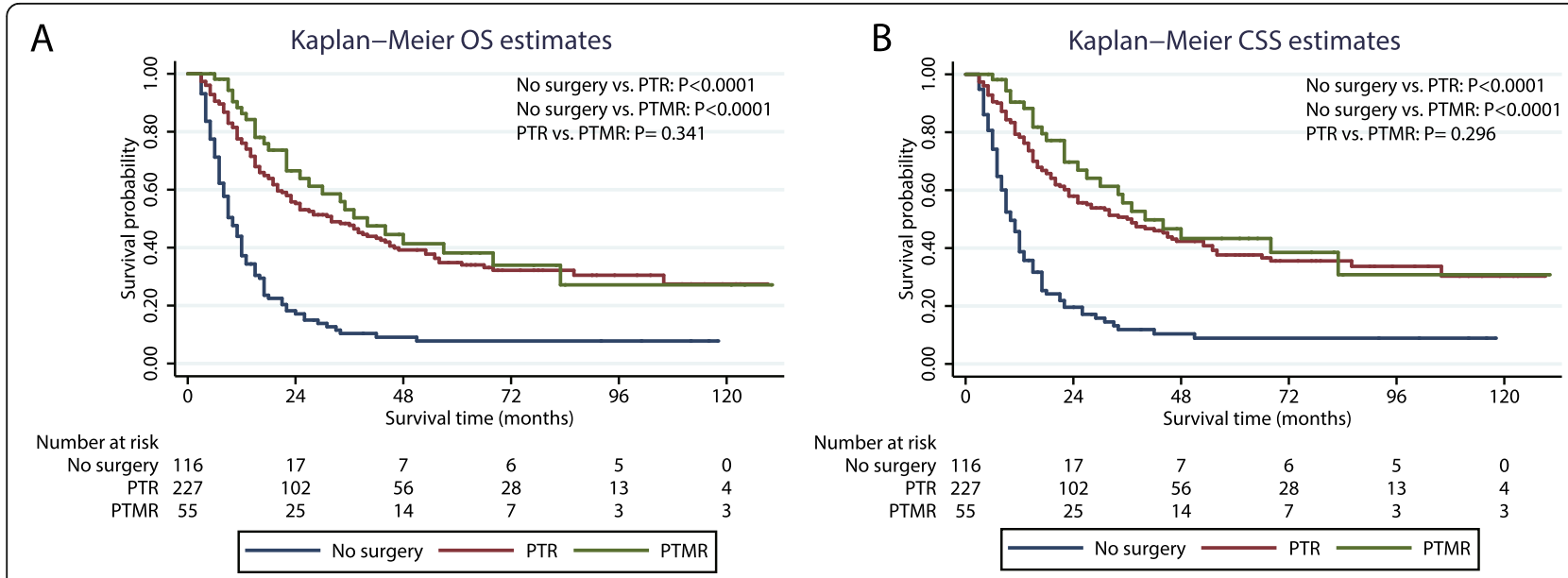

Fig. 3 Kaplan-Meier survival analysis. Shown are curves comparing the (a) OS and (b) CSS between the non-regional dissection group, PTR group, and PTMR group. OS: overall survival; CSS: cause-specific survival; PTR: primary tumour resection; PTMR: primary tumour and metastatic site resection 


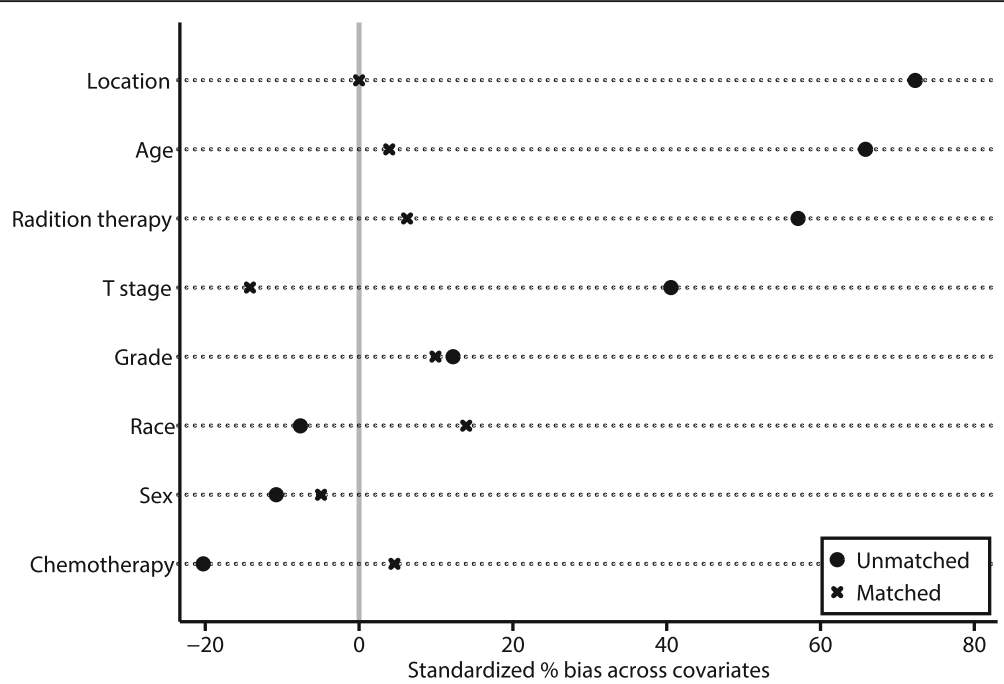

Fig. 4 Standardised bias test. The standardised bias (\%) across covariates before and after propensity score matching show that the candidate covariates were well matched

circulating tumour cells (CTCs) colonised their site of origin, which is known as "tumour self-seeding" [20]. Furthermore, the CTCs, which accelerate metastatic tumour formation [21], can alter the microenvironment, making it more favourable for tumour growth without further adaptation [19]. Tumour self-seeding by CTCs has been reported in osteosarcomas [22], and therefore, primary tumours should be excised to reduce the CTCs. We found that compared to the non-regional dissection of metastatic osteosarcomas, the regional dissection of primary tumours may be a more appropriate approach to promote survival.

The Cooperative German-Austrian-Swiss Osteosarcoma Study Group showed that concomitant regional dissection of primary tumours can improve the effectiveness of chemotherapy in patients with metastatic osteosarcoma [23] . Some other studies suggested that surgical resection of all detectable neoplasms contributed to better prognosis $[6,24]$. Surgical dissection of all metastatic sites has, therefore, been recommended for patients with metastatic osteosarcoma [25, 26]. Studies have also indicated that the aggressive resection of tumours, both primary and metastatic, improves the patient's response to chemotherapy [27-29]. In this study, we demonstrated that patients who underwent PTR or PTMR had better survival than those who did not undergo regional resection. However, we found no significant difference in the survival outcomes following PTR versus PTMR. Therefore, the choice of surgical method depends on individual circumstances. For instance, it is not advisable for a metastatic osteosarcoma

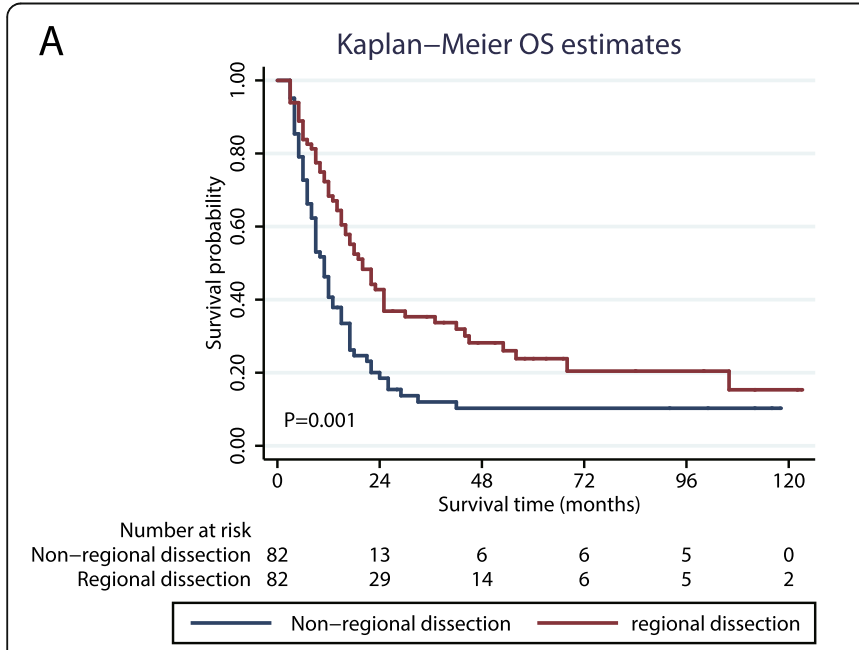

B

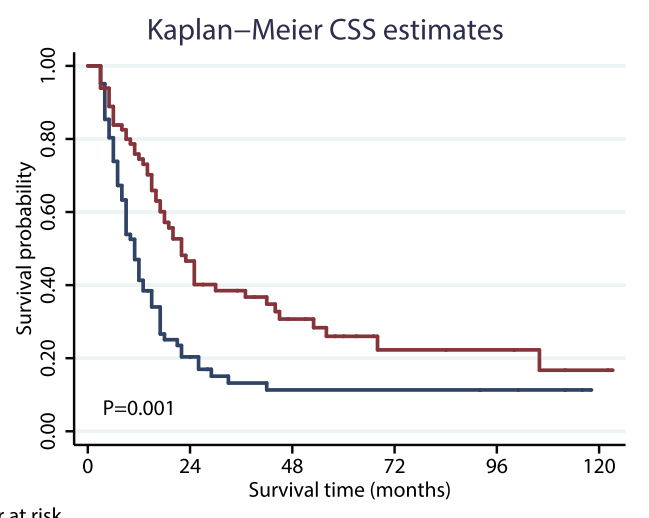

Number at risk

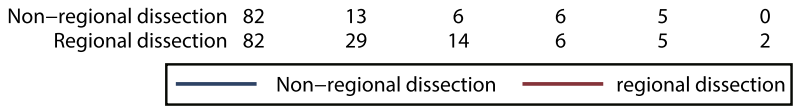

Fig. 5 Kaplan-Meier survival analysis. Shown are the curves for (a) OS and (b) CSS based on the primary tumour local treatment status in the matched population. OS: overall survival; CSS: cause-specific survival 
patient with poor physical condition to undergo complete surgical dissection of all detected tumours if the survival time following the dissection is comparable to that of patients undergoing PTR. This is because a complete surgery, such as PTMR, results in more complications and pain that can last a lifetime. Furthermore, PTR is a less difficult procedure for the doctor to perform and has a higher success rate than PTMR. Other studies have also proposed that patients with diseases in multiple sites should not undergo complete surgical dissection because of poor prognosis [6]. Compared to PTMR, PTR, therefore, is more appropriate for such patients and is associated with similar survival rates. Studies have shown that palliative surgical resection can help alleviate symptoms, provide pain relief, and improve survival outcomes [30].

We did not include the quality of life after surgical resection in our analysis. However, we suggest that it should be taken into account since surgery-related complications tend to have adverse effects on the quality of life. In patients with comparable survival outcomes, improvement in the quality of life is important [31]. For comprehensive care, it is also important to consider patient preferences and hospital costs before implementing treatments.

This study has several limitations. Some variates such as response to chemotherapy and the general state of health, which are related to survival, were not recorded in the SEER database. The SEER database also lacked clarification regarding specific procedures used for surgical resection such as limb-sparing surgery and amputation, which may have led to differences in the quality of life. Moreover, there could have been unobserved confounders that were probably not adjusted for in this analysis. For example, doctors may prefer a certain surgical treatment for patients with better prognosis. This selection bias may have a potential effect on the outcome of resection and might make results look better than they actually were. If the underlying prognostic variables were known, PSM could be used to reduce the effect of these biases. Despite these limitations, we have reduced the biases and errors as far as possible by using effective measures such as Kaplan-Meier plot before and after PSM, as well as univariate and multivariate analyses.

\section{Conclusions}

In conclusion, patients in the regional dissection group, including the PTR and PTMR subgroups, had better OS and CSS than those in the non-regional dissection group based on the case-matched analysis. Furthermore, PTR was more appropriate than PTMR for patients with metastatic osteosarcoma who had comparable survival rates. However, further clinical studies are required to confirm these findings.

\begin{abstract}
Abbreviations
Cl: Confidence interval; CSS: Cancer-specific survival; CTCs: circulating tumour cells; HR: Hazard ratio; OS: Overall survival; PSM: Propensity score matching; PTMR: Primary tumour and metastatic site resection; PTR: Primary tumour resection; SEER: Surveillance, Epidemiology, and End Results; SPSS: Statistical package for the social sciences
\end{abstract}

\section{Acknowledgements}

The authors acknowledge the efforts of the group who created the SEER database. We also acknowledge Wenjuan Wang, Hongzhi Ding, Zhenyu Sun, Chen Jin, Fancheng Chen, Yanhui Zhu and Xiang Wang who contributed to this manuscript.

\section{Authors' contributions}

WW contributed significantly to analysis and manuscript preparation, HD performed the data analyses and wrote the manuscript, ZS helped perform the analysis with constructive discussions, CJ contributed to manuscript preparation, FC participated in discussions, $Y Z$ contributed to the conception of the study, and XW contributed to the conception of the study. All authors read and approved the final manuscript.

Funding

The study was funded by the Natural Science Foundation of Shanghai (17ZR1416600).

\section{Availability of data and materials}

Data used in this study were obtained from the SEER database. The private SEER ID (13130-Nov 2017) was used to support our analysis.

\section{Ethics approval and consent to participate}

All procedures performed in studies involving human participants were in accordance with the ethical standards of the institutional and/or national research committee and with the 1964 Helsinki declaration and its later amendments or comparable ethical standards.

\section{Competing interests}

The authors declare that they have no competing interests.

\section{Author details}

${ }^{1}$ Shanghai Key Laboratory of Orthopaedic Implants, Shanghai Ninth People's Hospital, Shanghai Jiao Tong University School of Medicine, Shanghai, China. 2Department of Orthopaedic Surgery, Shanghai Ninth People's Hospital, Shanghai Jiao Tong University School of Medicine, Shanghai, China.

Received: 18 July 2019 Accepted: 13 February 2020

Published online: 13 March 2020

\section{References}

1. Wadhwa N. Osteosarcoma: Diagnostic dilemmas in histopathology and prognostic factors. Indian journal of orthopaedics. 2014;48(3):247-54. https:// doi.org/10.4103/0019-5413.132497.

2. Meazza C, Cefalo G, Massimino M, Daolio P, Pastorino U, Scanagatta P, Morosi C, Podda M, Ferrari A, Terenziani M, Spreafico F, Casanova M, Parafioriti A, Collini P, Gandola L, Bastoni S, Biassoni V, Schiavello E, Chiaravalli S, Puma N, Bergamaschi L, Luksch R. Primary metastatic osteosarcoma: results of a prospective study in children given chemotherapy and interleukin-2. Med Oncol. 2017;34(12):191. https://doi. org/10.1007/s12032-017-1052-9.

3. Guenther LM, Rowe RG, Acharya PT, Swenson DW, Meyer SC, Clinton CM, Guo D, Sridharan M, London WB, Grier HE, Ecklund K, Janeway KA. Response Evaluation Criteria in Solid Tumors (RECIST) following neoadjuvant chemotherapy in osteosarcoma. Pediatr Blood Cancer. 2018;65(4). https:// doi.org/10.1002/pbc.26896.

4. Endicott AA, Morimoto LM, Kline CN, Wiemels JL, Metayer C, Walsh KM. Perinatal factors associated with clinical presentation of osteosarcoma in children and adolescents. Pediatr Blood Cancer. 2017;64(6). https://doi.org/ 10.1002/pbc.26349.

5. Arndt CA, Rose PS, Folpe AL, Laack NN. Common musculoskeletal tumors of childhood and adolescence. Mayo Clin Proc. 2012;87(5):475-87. https://doi. org/10.1016/j.mayocp.2012.01.015. 
6. Meazza C, Scanagatta P. Metastatic osteosarcoma: a challenging multidisciplinary treatment. Expert Rev Anticancer Ther. 2016;16(5):543-56. https://doi.org/10.1586/14737140.2016.1168697.

7. Puri A, Byregowda S, Gulia A, Crasto S, Chinaswamy G. A study of 853 high grade osteosarcomas from a single institution-Are outcomes in Indian patients different? J Surg Oncol. 2018;117(2):299-306. https://doi.org/10. 1002/jso.24809.

8. Bedetti B, Wiebe K, Ranft A, Aebert H, Schmidt J, Jurgens H, Dirksen U. Local control in Ewing sarcoma of the chest wall: results of the EURO-EWING 99 trial. Ann Surg Oncol. 2015;22(9):2853-9. https://doi.org/10.1245/s10434-0154630-0.

9. Morris CD, Teot LA, Bernstein ML, Marina N, Krailo MD, Villaluna D, Janeway KA, DuBois SG, Gorlick RG, Randall RL. Assessment of extent of surgical resection of primary high-grade osteosarcoma by treating institutions: A report from the Children's Oncology Group. J Surg Oncol. 2016;113(4):3514. https://doi.org/10.1002/jso.24145.

10. Farfalli GL, Albergo Jl, Lobos PA, Smith DE, Streitenberger PD, Pallotta Rodriguez MG, Aponte-Tinao LA. Osteosarcoma lung metastases. Survival after chemotherapy and surgery. Medicina (B Aires). 2015;75(2):87-90.

11. Harrison DJ, Geller DS, Gill JD, Lewis VO, Gorlick R. Current and future therapeutic approaches for osteosarcoma. Expert Rev Anticancer Ther. 2018; 18(1):39-50. https://doi.org/10.1080/14737140.2018.1413939.

12. Lee JA, Paik EK, Seo J, Kim DH, Lim JS, Yoo JY, Kim MS. Radiotherapy and gemcitabine-docetaxel chemotherapy in children and adolescents with unresectable recurrent or refractory osteosarcoma. Jpn J Clin Oncol. 2016; 46(2):138-43. https://doi.org/10.1093/jjco/hyv171.

13. Plyku D, Loeb DM, Prideaux AR, Baechler S, Wahl RL, Sgouros G, Hobbs RF. Strengths and Weaknesses of a Planar Whole-Body Method of (153)Sm Dosimetry for Patients with Metastatic Osteosarcoma and Comparison with Three-Dimensional Dosimetry. Cancer Biother Radiopharm. 2015;30(9):36979. https://doi.org/10.1089/cbr.2014.1803.

14. Magnan H, Goodbody CM, Riedel E, Pratilas CA, Wexler LH, Chou AJ. Ifosfamide dose-intensification for patients with metastatic Ewing sarcoma. Pediatr Blood Cancer. 2015;62(4):594-7. https://doi.org/10.1002/pbc.25373.

15. Casey DL, Wexler LH, Meyers PA, Magnan H, Chou AJ, Wolden SL. Radiation for bone metastases in Ewing sarcoma and rhabdomyosarcoma. Pediatr Blood Cancer. 2015;62(3):445-9. https://doi.org/10.1002/pbc.25294.

16. Kempf-Bielack B, Bielack SS, Jurgens H, Branscheid D, Berdel WE, Exner GU, Gobel U, Helmke K, Jundt G, Kabisch H, Kevric M, Klingebiel T, Kotz R, Maas R, Schwarz R, Semik M, Treuner J, Zoubek A, Winkler K. Osteosarcoma relapse after combined modality therapy: an analysis of unselected patients in the Cooperative Osteosarcoma Study Group (COSS). Journal of clinical oncology : official journal of the American Society of Clinical Oncology. 2005;23(3):559-68. https://doi.org/10.1200/JCO.2005.04.063.

17. Briccoli A, Rocca M, Salone M, Guzzardella GA, Balladelli A, Bacci G. High grade osteosarcoma of the extremities metastatic to the lung: long-term results in 323 patients treated combining surgery and chemotherapy, 19852005. Surg Oncol. 2010;19(4):193-9. https://doi.org/10.1016/j.suronc.2009.05. 002.

18. Toledo-Pereyra LH. The scientific surgeon. J Investig Surg. 2011;24(1):1-3. https://doi.org/10.3109/08941939.2011.545715.

19. Comen E, Norton L, Massague J. Clinical implications of cancer self-seeding. Nat Rev Clin Oncol. 2011;8(6):369-77. https://doi.org/10.1038/nrclinonc.2011. 64.

20. Kim MY, Oskarsson T, Acharyya S, Nguyen DX, Zhang XH, Norton L, Massague J. Tumor self-seeding by circulating cancer cells. Cell. 2009;139(7): 1315-26. https://doi.org/10.1016/j.cell.2009.11.025.

21. Micalizzi DS, Maheswaran S, Haber DA. A conduit to metastasis: circulating tumor cell biology. Genes Dev. 2017;31(18):1827-40. https://doi.org/10.1101/ gad.305805.117

22. Zhang Y, Ma Q, Liu T, Ke S, Jiang K, Wen Y, Ma B, Zhou Y, Fan Q, Qiu X. Tumor self-seeding by circulating tumor cells in nude mouse models of human osteosarcoma and a preliminary study of its mechanisms. J Cancer Res Clin Oncol. 2014;140(2):329-40. https://doi.org/10.1007/s00432-0131561-7.

23. Kager L, Zoubek A, Potschger U, Kastner U, Flege S, Kempf-Bielack B, Branscheid D, Kotz R, Salzer-Kuntschik M, Winkelmann W, Jundt G, Kabisch H, Reichardt P, Jurgens H, Gadner H, Bielack SS, Cooperative GermanAustrian-Swiss Osteosarcoma Study G. Primary metastatic osteosarcoma: presentation and outcome of patients treated on neoadjuvant Cooperative Osteosarcoma Study Group protocols. Journal of clinical oncology : official journal of the American Society of Clinical Oncology. 2003;21(10):2011-8. https://doi.org/10.1200/JCO.2003.08.132.

24. Beckers PAJ, Versteegh MIM, Van Brakel TJ, Braun J, Van Putte B, Maat A, Vergauwen W, Rodrigus I, Den Hengst W, Lardon F, De Bruijn E, Guetens G, De Boeck G, Gielis JF, Lauwers P, Denissen L, Hendriks JMH, Van Schil PE. Multicenter Phase II Clinical Trial of Isolated Lung Perfusion in Patients With Lung Metastases. Ann Thorac Surg. 2019;108(1):167-74. https://doi.org/10. 1016/j.athoracsur.2019.02.071.

25. Ritter J, Bielack SS. Osteosarcoma. Ann Oncol. 2010;21(Suppl 7):vii320-5. https://doi.org/10.1093/annonc/mdq276.

26. Leary SE, Wozniak AW, Billups CA, Wu J, McPherson V, Neel MD, Rao BN, Daw NC. Survival of pediatric patients after relapsed osteosarcoma: the St. Jude Children's Research Hospital experience. Cancer. 2013;119(14):2645-53. https://doi.org/10.1002/cncr.28111.

27. Harrison DJ, Schwartz CL. Osteogenic Sarcoma: Systemic Chemotherapy Options for Localized Disease. Curr Treat Options in Oncol. 2017;18(4):24. https://doi.org/10.1007/s11864-017-0464-2.

28. Senerchia AA, Macedo CR, Ferman S, Scopinaro M, Cacciavillano W, Boldrini E, Lins de Moraes VL, Rey G, de Oliveira CT, Castillo L, Almeida MT, Borsato ML, Lima E, Lustosa D, Barreto JH, El-Jaick T, Aguiar S, Brunetto A, Greggiani L, Cogo-Moreira H, Atallah A, Petrilli AS. Results of a randomized, prospective clinical trial evaluating metronomic chemotherapy in nonmetastatic patients with high-grade, operable osteosarcomas of the extremities: A report from the Latin American Group of Osteosarcoma Treatment. Cancer. 2017;123(6):1003-10. https://doi.org/10.1002/cncr.30411.

29. Bishop MW, Chang YC, Krailo MD, Meyers PA, Provisor AJ, Schwartz CL, Marina NM, Teot LA, Gebhardt MC, Gorlick R, Janeway KA, Chou AJ. Assessing the Prognostic Significance of Histologic Response in Osteosarcoma: A Comparison of Outcomes on CCG-782 and INT0133-A Report From the Children's Oncology Group Bone Tumor Committee. Pediatr Blood Cancer. 2016;63(10):1737-43. https://doi.org/10.1002/pbc. 26034.

30. Traub F, Singh J, Dickson BC, Leung S, Mohankumar R, Blackstein ME, Razak AR, Griffin AM, Ferguson PC, Wunder JS. Efficacy of denosumab in joint preservation for patients with giant cell tumour of the bone. Eur J Cancer. 2016;59:1-12. https://doi.org/10.1016/j.ejca.2016.01.006.

31. Utyuzh AS, Yumashev AV, Lang HW, Zekiy AO, Lushkov RM. Comprehensive Treatment and Rehabilitation of Patients With Osteosarcoma of the Mandible. Implant Dent. 2018;27(3):332-41. https://doi.org/10.1097/ID. 0000000000000756

\section{Publisher's Note}

Springer Nature remains neutral with regard to jurisdictional claims in published maps and institutional affiliations.

Ready to submit your research? Choose BMC and benefit from:

- fast, convenient online submission

- thorough peer review by experienced researchers in your field

- rapid publication on acceptance

- support for research data, including large and complex data types

- gold Open Access which fosters wider collaboration and increased citations

- maximum visibility for your research: over $100 \mathrm{M}$ website views per year

At $\mathrm{BMC}$, research is always in progress.

Learn more biomedcentral.com/submissions 